九州大学学術情報リポジトリ

Kyushu University Institutional Repository

\title{
Volatile Components Recovered from Fresh Onion (Allium cepa L.) with Combination of Ethyl Ether Extraction and New Cold Trap Apparatus
}

Ohta, Hideaki

Chugoku National Agricultural Experiment Station, Ministry of Agriculture, Forestry and Fisheries

Osaj ima, Yutaka

Laboratory of Food Analysis, Faculty of Agriculture, Kyushu University

https://doi.org/10.5109/24003

出版情報：九州大学大学院農学研究院紀要. 37 (2)，pp. 125-131，1992-12. Kyushu University バージョン：

権利関係 : 


\title{
Volatile Components Recovered from Fresh Onion (Allium cepa $L$.) with Combination of Ethyl Ether Extraction and New Cold Trap Apparatus
}

\author{
Hideaki Ohta* and Yutaka Osajima \\ Laboratory of Food Analysis, Faculty of Agriculture, \\ Kyushu University 46-09, Fukuoka 812, Japan \\ (Received June 30, 1992)
}

\begin{abstract}
One of the problems in extracting flavor compounds from plant materials with an organic solvent is that the solvent extract concentrate becomes an emulsion and highly viscous liquid, making it difficult to recover the volatile flavor compounds from the extract concentrate. We produced a new cold trap apparatus to recover volatile compounds from such an extract concentrate. In this study, volatile flavor compounds recovered from sliced fresh onion with a combination of ethyl ether extraction and this cold trap apparatus were investigated by capillary gas chromatography (GC) and GC-mass spectrometry. Fifly one peaks was detected and 24 of them were identified. The major sulfur-containing compounds consisted of trans-propenyl propyl disulfide, dipropyl disulfide, dimethyl thiophene and cis-propenyl propyl disulfide. Thus, the combination of ethyl ether extraction and this new cold trap apparatus provided a useful procedure for preparing samples.
\end{abstract}

\section{INTRODUCTION}

Recovery of flavor compounds from plant materials prior to gas chromatographic analysis is one of most important factors in flavor chemistry, and the development of glass capillary gas chromatography (GC) and GC-mass spectrometry (MS) have greatly contributed to advances in flavor analytical chemistry (Tugita and Katoh, 1983). The concentration and nature of the flavor compounds often depend on sample preparation methods. Three general procedures have been used for isolating the flavor compounds (Tugita and Katoh, 1983). One method involves analysis of the head space above the sample. Another method involves steam distillation of the sample. The third method involves the extraction of the sample with a low-boiling organic solvent followed by evaporation of the solvent. Of the three methods, the solvent extraction procedure has been widely used for plant materials (Brodnitz et. al., 1971; Ohta and Osajima, 1983). One problem in extracting the sample with organic solvent, however, is that the extract concentrates often becomes an emulsions and highly viscous liquid, and that it is very difficult to inject directly such an extract concentrate into the GC. Therefore, the volatile flavor compounds should be recovered from the extract by another method.

* Chugoku National Agricultural Experiment Station, Ministry of Agriculture, Forestry and Fisheries, Fukuyama-city, Hiroshima 721, Japan 
In the course of our study on flavor analysis of fruits and vegetables, we produced a new round bottomed-type cold trap apparatus to recover volatile flavor compounds from the solvent extract concentrate. We have applied this cold trap apparatus for recovering volatile flavor compounds in the fresh onion. This paper describes the identification of volatile components extracted from fresh onions with a combination of ethyl ether extraction and new cold trap apparatus, using a support coated open tubular (SCOT) glass capillary GC and GC-MS.

\section{MATERIALS AND METHODS}

\section{Onion}

Twenty kilograms of fresh onions (Allium cepa L.), cultivar "Zihibiki", was purchased from Seba Agricultural Cooperative Associations, Nagano Prefecture.

\section{Apparatus}

Figure 1 shows a schematic diagram of the new cold trap apparatus, consisting of a round-bottomed type trap cooled with dry-ice acetone and two normal type traps cooled with liquid nitrogen. The round flask contained the extract sample connected to the bottom of round bottomed type trap. The volatile fraction was cold-trapped under reduced pressure $(20 \mathrm{mmHg})$ at ambient temperature.

\section{Volatile flavor recovery from the onion}

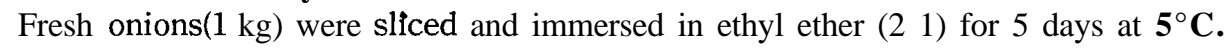
The sliced onion residue was extracted twice with 11 of ethyl ether. The combined ethyl ether extract was dehydrated overnight with sodium sulfate and the extract was concentrated in vacuo to approximately $100 \mathrm{ml}$. The volatile fraction was cold-trapped from the solvent extract concentrate, using the new cold trap apparatus. The flavor fraction recovered with a small amount of ethyl ether was concentrated again in vacuo.

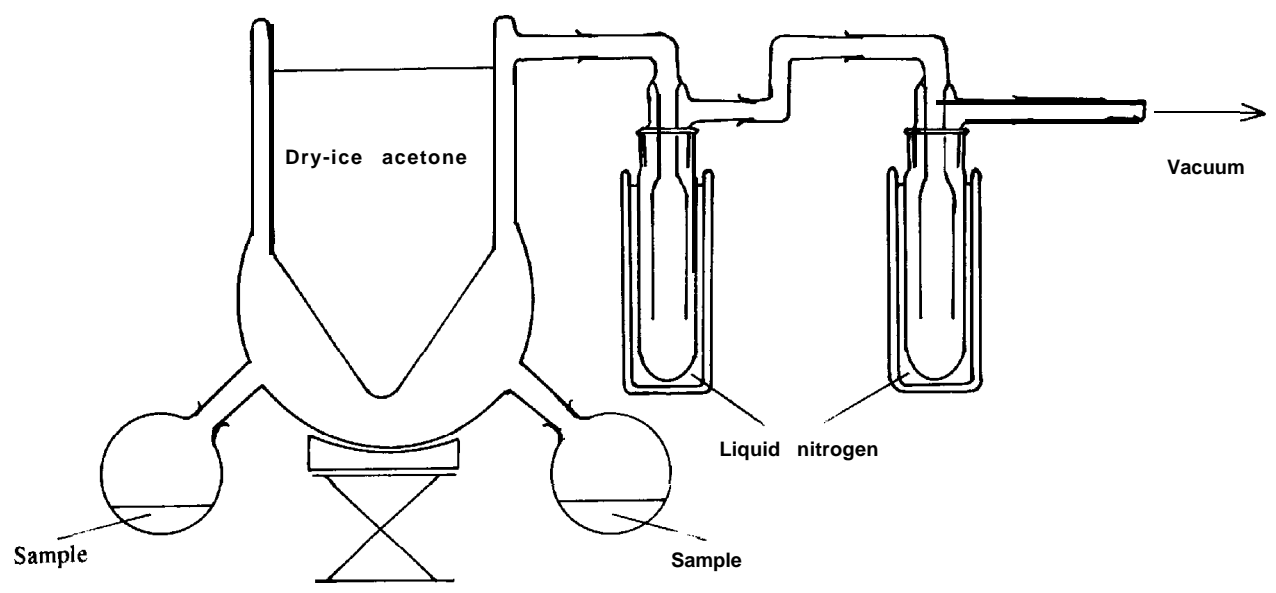

Fig. 1. A schematic diagram of the cold trap apparatus. 


\section{GC and GC-M S conditions}

Analytical GC was carried out on a Shimadzu Model 8A gas chromatograph equipped with both a flame ionization detector (FID) and a flame photometric detector (FPD). A SCOT glass capillary column $(25 \mathrm{~m} \times 0.25 \mathrm{~mm}$ I.D.) coated with Carbowax $20 \mathrm{M}$ was used. The temperature of both injection port and detector were maintained at $270^{\circ} \mathrm{C}$. The column oven temperature was programmed from $65^{\circ} \mathrm{C}$ to $195^{\circ} \mathrm{C}$ at $4^{\circ} \mathrm{C}$ $\min ^{-1}$. Nitrogen carrier gas was used at a flow rate of $0.92 \mathrm{ml} \mathrm{min}^{-1}$ with a split ratio of $92: 1$. The sample size was $0.2 \sim 1$. Peak area was integrated by a Shimadzu chromatopak C-R3A.

GC-MS analysis was performed on a Hitachi Model M-80A mass spectrometer combined with a Hitachi Model 063 gas chromatograph, under similar conditions to the GC analysis. Other operating parameters were as follows: carrier gas, helium; ionizing voltage $20 \mathrm{eV}$; ion source temperature, $200^{\circ} \mathrm{C}$.

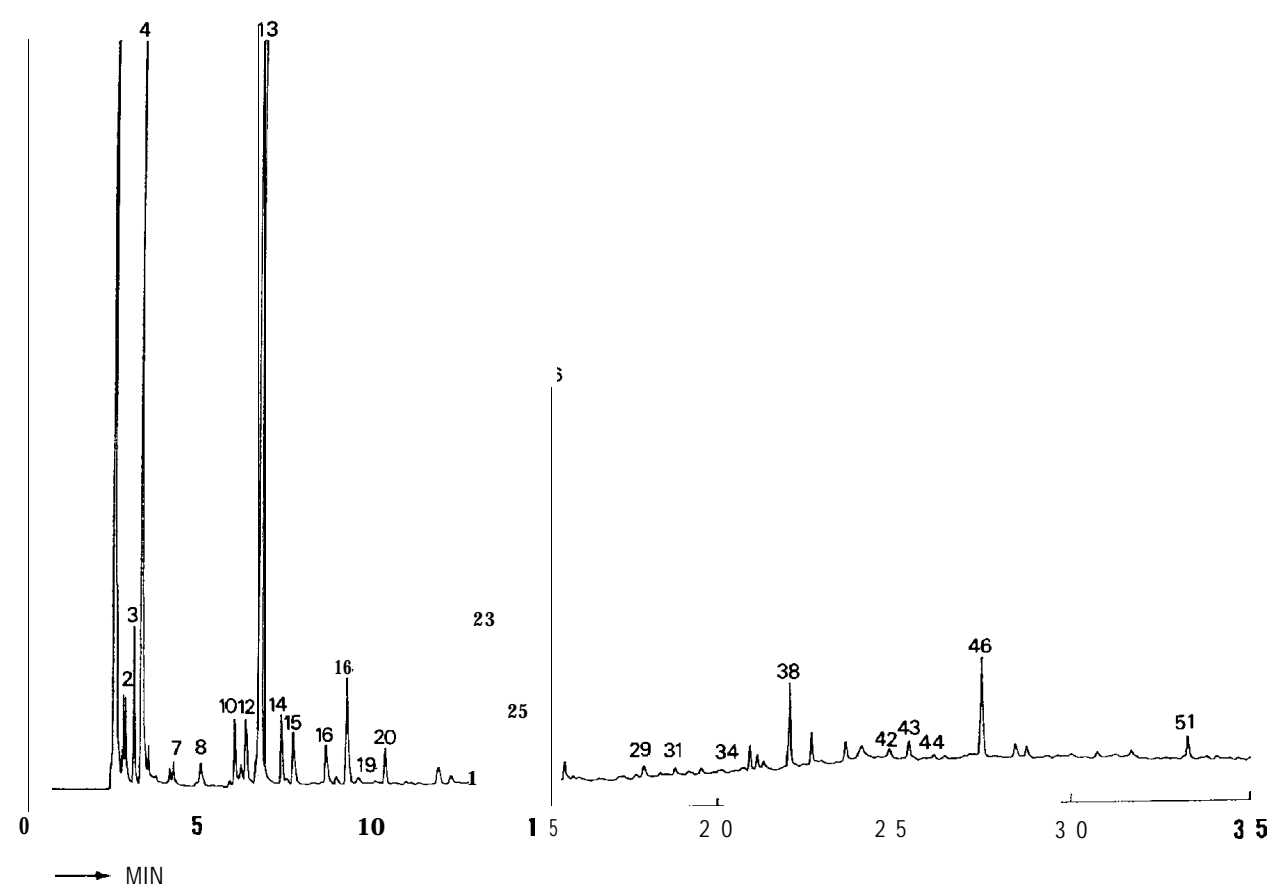

Fig. 2. Gas chromatogram recorded with a flame ionization detector (FID) of a volatile concentrate of fresh onions. A SCOT glass capillary column $(25 \mathrm{~m} \times 0.25 \mathrm{~mm}$ I.D.) coated with Carbowax $20 \mathrm{M}$ and FID were used. The column oven temperature was programmed from $65^{\circ} \mathrm{C}$ to $195^{\circ} \mathrm{C}\left(4^{\circ} \mathrm{C} \mathrm{min}^{-1}\right)$. Other operating conditions are in the Materials and Methods section and peak identities are given in Table 1. 
Table 1. Volatile compounds identified in the fresh onion.

\begin{tabular}{clrrr}
\hline \multirow{2}{*}{$\begin{array}{c}\text { Peak No. } \\
\text { in Fig. } 2\end{array}$} & \multicolumn{1}{c}{ Compound } & \multicolumn{2}{c}{$\begin{array}{c}\text { Peak } \\
\text { area }\end{array}$} & \multicolumn{2}{c}{ Evidence } \\
\cline { 3 - 5 } & & (\%) & GC & GC-MS \\
\hline 2 & Propionaldehyde & 0.88 & + & + \\
3 & Ethyl acetate & 1.44 & + & + \\
4 & Ethyl alcohol & 10.49 & + & + \\
6 & Propyl alcohol & 0.34 & + & + \\
8 & Isobutyl alcohol & 0.37 & + & + \\
10 & Isoamyl acetate & 1.15 & + & + \\
12 & Ethyl benzene & 1.14 & & + \\
13 & 2-Methyl-2-pentanal & 35.19 & + & + \\
15 & Isoamyl alcohol & 1.22 & & + \\
16 & Methyl propyl disulfide & 0.97 & + & + \\
18 & Dimethyl thiophene & 2.27 & & \\
19 & Methyl cis-propenyl disulfide & 0.19 & + & + \\
20 & Methyl trans-propenyl disulfide & 0.59 & + & + \\
23 & Dipropyl disulfide & 2.92 & + & + \\
25 & cis-Propenyl propyl disulfide & 1.19 & & + \\
26 & trans-Propenyl trisulfide & 7.95 & & + \\
29 & Methyl propenyl trisulfide & 0.39 & & + \\
31 & Ethyl nonanoate & 0.20 & & + \\
38 & 2-Undecanone & 0.10 & + & + \\
42 & Dipropyl trisulfide & 1.51 & + & + \\
43 & cis-3,5-Diethyl-1,2,4-trithiolane & 0.17 & + & + \\
44 & trans-3,5-Diethyl-1,2,4-trithiolane & 0.44 & + & + \\
46 & 2-Tridecanone & 0.15 & + & + \\
& Benzyl alcohol & 2.32 & + & + \\
\hline
\end{tabular}

\section{RESULTS AND DISCUSSION}

The yield of volatile concentrate was $4.2 \mathrm{ppm} ; 42 \mathrm{mg}$ of fresh weight of onion investigated.

Figure 2 shows gas chromatogram of a volatile concentrate $(0.2 \mu 1)$ of the onion sliced, using FID. Figure 3 presents a gas chromatogram using FPD, in order to detect the sulfur-containing components.

Fifty one peaks were demonstrated in the volatile concentrate of the onion. Twenty of these peaks were identified by comparing and matching the mass spectra and GC retention times, and four peaks were identified by the mass spectra alone.

Table 1 lists the components identified in the volatile concentrate recovered with the combination of both the ethyl ether extraction and the new cold trap apparatus. The peak area percentages without solvent peak (ethyl ether) were estimated by GC analysis with FID of the volatile concentrate. Peak numbers on the left-hand side give the elution order on the 25-m Carbowax 20M column (Fig. 2).

2-Methyl-2-pentanal (peak 13) and ethyl alcohol (peak 4) comprised $45.68 \%$ of the total peak area of the volatile concentrate. Aldehydes are generally responsible for food flavor. Boelens et al., (1971) reported that propylaldehyde is one of the more important flavor compounds in the raw onion. The high concentration of Z-methyl-2 -pentanal suggested that it played a more important role than propylaldehyde (peak 
$2,<1 \%$ ). The aldehydes were presumed to be formed due to an enzyme reaction (Whitaker, 1976).

Many researchers have studied the volatile flavor compounds of onion since Semmler in 1982 (Brodnitz et al., 1969 and 1971; Bernhard, 1968; Schwimmer and Guadagni, 1968; Nishimura et al., 1971 and 1973; Lukes, 1971; Mazza et al., 1980), pointing out that one of the outstanding features of the chemical components of the onion was the large amount of organic bound sulfur. The number of sulfur-containing compounds in onion is much larger than that usually found in most plants. In particular, these sulfur-containing compounds in onion have received attention because of their potential antibiotic and flavor properties (Whitaker, 1976). Fig 3 shows a gas chromatogram recorded with FPD of a volatile concentrate, to confirm the sulfurcontaining compounds. The eleven organic sulfur compounds identified in this study accounted for $18.6 \%$ of the total peaks, and had the characteristic odor of fresh onions. The principal disulfide was trans-propenyl propyl disulfide, followed in descending order of concentration by dipropyl disulfide, cis-propenyl propyl disulfide, methyl propyl disulfide, methyl trans-propenyl propyl disulfide and methyl cis-propenyl propyl disulfide. Of the trisulfides identified, the amount of dipropyl trisulfide was larger than that of methyl propyl trisulfides. Two unique cyclic sulfur compounds, trans- and cis-3,5-diethyl-1,2,4-trithiolane which were reported by Kameoka and

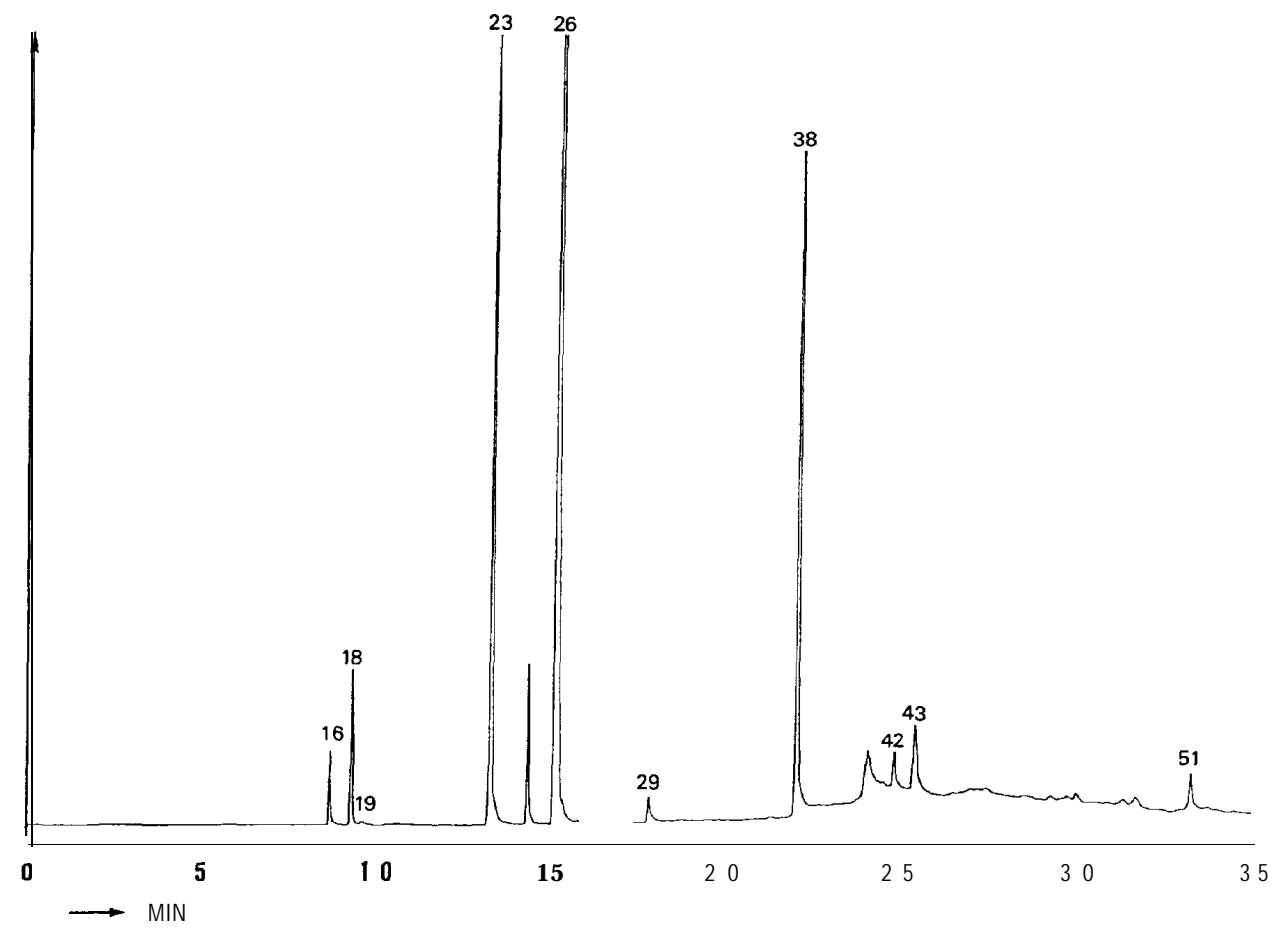

Fig. 3. Gas chromatogram recorded with a flame photometric detector (FPD) of a volatile concentrate of fresh onion. See Fig. 2 for GC conditions. 
Demizu (1979), were also found in this recovered fraction from freshly cut onions. These disulfides, trisulfides, thiophene and thiolane are primarily responsible for the odor and flavor characteristics of onion (Whitaker, 1976).

These sulfur-containing compounds are secondarily formed from the primary sulfur-containing products of alliinase action. In onion, the major primary compound is trans-( +)-S-(1-propenyl)-L-cysteine sulfoxide, as widely known flavor and lachrymatory precursor (Whitaker, 1976).

In this study, the solvent extraction procedure was employed to recover flavor compounds from freshly sliced onions followed by a cold trap apparatus, since the solvent extraction concentrate became an emulsion and viscous liquid before injection into the GC. This high viscosity of extract concentrate was presumably due to sugars and proteins contained in the freshly sliced onions. It was, therefore, necessary to recover the flavor compounds from this extract concentrate. Finally, typical sulfurcontaining and aldehyde compounds, which contributed to the characteristic odor in onion, could be detected, even though the 51 peaks were detected in this study. The recovery method using this cold trap apparatus effectively characterized the flavor of onion.

In conclusion, the present findings clearly indicate that the combination of both solvent extraction and new cold trap apparatus is a useful and convenient method to recover the flavor components from plant materials.

\section{REFERENCES}

Bernhard, R.A. 1968 Comparative distribution of volatile aliphatic disulfides derived from fresh and dehydrated onion. J. Food Sci., 33: 298-304

Boelens, M., P.J. de Valois, H.J. Wobben and A. van der Gen 1971 Volatile flavor compounds from onion. J. Agric. Food Chem., 19: 984-991

Brodnitz, M.H. and J.V. Pascale 1971 Thiopropanal S-oxide : A Lachrymatory factor in onion. J. Agric. Food Chem., 19: 269-272

Brodnitz, M.H., C.L. Pollock and P.P. Vallon 1969 Flavor components of onion oil. J. Agric. Food Chem., 17: 760-763

Kameoka, H. and Y. Demizu 1979 3,5-Diethyl-1,2,4-trithiolane from Allium cepa. Phytochem., 18: 1397-1398

Lukes, T.M. 1971 Thin-layer chromatography of cysteine derivatives of onion flavor compounds and the lachrymatory factor. J. Food Sci., 36: 662-664

Mazza, G., M. LeMaguer and D. Hadziyev 1980 Headspace sampling procedure for onion (Allium cepa $\mathrm{L}$ ) aroma assessment. Can. Inst. Food Sci. Technol. J., 13: 87-96

Nishimura, H., A. Asahi, K. Fujiwara, J. Mizutani and Y. Obata 1971 Changes in flavor components of onion by y-irradiation. Agric. Biol. Chem., 35: 1831-1835

Nishimura, H., S. Koike and J. Mizutani 1973 Mass spectra of volatile sulfur compound in foods. Agric. Biol. Chem., 37: 1219-1220

Ohta, H. and Y. Osajima 1983 Glass capillary gas chromatographic analysis of oil components extracted from Yuzu (Citrus junos) juice. J. Chromatogr., 263: 336-340

Semmler, F.W. 1982 The essential oil of onion (Allium cepa L.). Arch, Pharmacol., 230: 434-443

Schwimmer, S. and D.F. Guadagni 1968 Kinetics of the enzymatic development of pyruvic acid and odor in frozen onions treated with cysteine C-S lyase., J. Food Sci., 33: 193-196 
Tugita, T. and Katoh, H. 1983 New Techniques for volatile flavor analysis and their applications, 2 Condensation of flavor element and its extraction from foods. The Food Industry, 26(4): 57-62 (in' Japanese)

Whitaker, J.R. 1976 development of flavor, odor, and pungency in onion and garlic. In "Advances in Food Research", Vol. 22, ed. by C.O. Chichester, Academic Press, Inc., New York, pp. 73-133 